\title{
Editorial for the JMMA, Number 1, 2012
}

\author{
Vic Rayward-Smith
}

Received: 15 January 2012 / Accepted: 16 January 2012 / Published online: 31 January 2012

(C) Springer Science+Business Media B.V. 2012

The JMMA has been growing steadily over the last two years with an increased number of submissions from all over the world. The quality of our published papers has remained high and we continue to enjoy a healthy number of downloads and citations. However, we have found it increasingly difficult to maintain our commitment to a truly multi-disciplinary journal. Referees have been difficult to recruit for some of our papers and the journal's impact has been spread too thinly over diverse research areas.

The majority of our published papers are in the field of Operations Research and we have decided that we will have to focus our attention on this particular topic of research. Accordingly, the name of the journal will be changed to the "Journal of Mathematical Modelling and Algorithms in Operations Research" from the beginning of 2013; it will however retain its abbreviated title of JMMA. From now on, we will only consider submissions that fall under the operations research umbrella.

The JMMA will be taking the term "Operations Research" in its widest context, welcoming papers in mathematical programming: linear, integer, fractional, nonlinear, dynamic, and multi-objective programming, heuristic and metaheuristic techniques; probabilistic approaches: Bayesian approaches and multi-criteria decision analysis, simulation and stochastic processes; datamining and machine learning; network and graph algorithms. The journal will continue to welcome papers that describe novel modelling and/or algorithmic techniques and will particularly welcome papers that describe applications to real world problems. Accepted papers will generally be in-depth studies and will always be written in a good standard of English. However, for authors whose first language is not English, some assistance will be available should that be needed.

Given the new focus of the JMMA, it has been necessary to restructure the editorial board. The new board will commence its duties with immediate effect and,

V. Rayward-Smith $(\varangle)$

University of East Anglia, Norwich, UK

e-mail: vjrs@uea.ac.uk 
as editor-in-chief, I am grateful to them for their support and advice. Their input, and especially that of the North American editor, Jim MacGregor Smith, has been invaluable in the refocusing of the journal and I look forward to working with them in the future. I also wish to record very sincere thanks to those members of the board who are leaving the JMMA. Most have been with us since the journal's inception and have provided unstinting and unconditional support for the journal.

We continue to rely on large number of referees outside the editorial board. I am enormously grateful to these anonymous stalwarts who give their time and advice without fee and without recognition. Their work illustrates the strength and goodwill within the research community. Without their help, the JMMA and similar journals could not exist and academic publishing as we know it would collapse.

Our final thanks go to our authors, who continue to submit the best of their research to the journal, and to our readers and subscribers, who find the papers useful in their own work. We hope you will appreciate the new focus of the journal and we look forward to your continued support.

Vic Rayward-Smith 1st January 2012 